\title{
Reação de híbridos de pepino a Corynespora cassiicola no Amazonas.
}

\author{
Elisângela de Jesus da Silva Bezerra ${ }^{1}$; Jânia Lília da Silva Bentes ${ }^{1 *}$
}

${ }^{1}$ Universidade Federal do Amazonas-Faculdade de Ciências Agrárias, Av. Rodrigo Otávio 6200-Coroado. CEP69077-000, Manaus-AM. Autor para correspondência: Jânia Lília da Silva Bentes (jlbentes@ufam.edu.br)

Data de chegada: 01/07/2014. Aceito para publicação em: 19/12/2014.

$10.1590 / 0100-5405 / 2016$

\section{RESUMO}

Bezerra, E.J.S.; Bentes, J.L.S. Reação de híbridos de pepino a Corynespora cassiicola no Amazonas. Summa Phytopathologica, v.41, n.1, p.71-72, 2015.

A mancha-alvo, causada pelo fungo Corynespora cassiicola, é a principal doença da parte área do tomateiro na região Norte do Brasil. No Estado do Amazonas o patógeno em plantas de pepino, causa severos danos à produção tanto em cultivo protegido quanto em campo aberto. $\mathrm{O}$ objetivo deste trabalho foi avaliar a reação de dez genótipos de pepino a C. cassiicola. O experimento foi conduzido em casa de vegetação em delineamento inteiramente ao acaso com dez tratamentos e dez repetições. Foram avaliados a cultivar Aodai e os híbridos tipo japonês General Lee F1, Hokushim, Japonês Híbrido F1 (Soudai), Jóia, Marketmore 76 (verde comprido), Natsubayashi, Natsu Suzumi, Sprint 440 II e Tsuyataro. Os isolados do patógeno foram obtidos a partir de folhas de plantas de pepino naturalmente infectadas, e multiplicado em meio de cultura BDA. As plantas foram inoculadas nas duas primeiras folhas definitivas com suspensão de inóculo na concentração $10^{4}$ conídios $\mathrm{mL}^{-1}$ e mantidas em câmara úmida por 48 horas. A severidade foi avaliada e calculada a área abaixo da curva de progresso da doença (AACPD) para cada tratamento. Houve variação na reação dos genótipos ao patógeno e a cultivar Aodai apresentou menor AACPD considerada como resistente. Os híbridos Hokuchim, Soudai, Verde Comprido e Natsubayashi apresentaram menores valores de AACPD entre os híbridos avaliados em contraposição ao Tsuyataro o mais suscetível.

Palavras-chave adicionais: Mancha-alvo, Cucumis sativus, resistência.

\section{ABSTRACT}

Bezerra, E.J.S.; Bentes, J.L.S. Reaction of cucumber hybrids to Corynespora cassiicola in Amazonas. Summa Phytopathologica, v.41, n.1, p.71-72, 2015.

The target spot caused by the fungus Corynespora cassiicola is the major disease affecting tomato shoot in the north region of Brazil. In Amazonas State, this pathogen has caused severe damage to the production of cucumber plants, both in greenhouses and in the field. The aim of this study was to evaluate the reaction of ten cucumber genotypes to $C$. cassiicola. The experiment was conducted in a greenhouse, and a completely randomized design with ten treatments and ten replicates was adopted. The following cucumber cultivar and hybrids were evaluated: cultivar Aodai, and hybrids Japanese General Lee F1, Hokushim, Japanese Hybrid F1 (Soudai), "Jóia", Marketmore 76 (long green), Natsubayashi, Natsu Suzumi, Sprint 440
II and Tsuyataro. The pathogen isolates were obtained from leaves of naturally infected cucumber plants and multiplied on PDA culture medium. The plants had their first two definitive leaves inoculated with inoculum suspension at the concentration of $10^{4}$ conidia $\mathrm{mL}^{-1}$ and kept in a humid chamber during 48 hours. Severity was assessed and the area under the disease progress curve (AUDPC) was calculated for each treatment. There was variation in the reaction of genotypes to the pathogen, and cultivar Aodai showed the smallest AUDPC, considered resistant. The hybrids Hokuchim, Soudai, Long Green and Natsubayashi presented the lowest AUDPC values in contrast to Tsuyataro, the most susceptible hybrid.

Additional keywords: Target spot, Cucumis sativus, resistance.

Corynespora cassiicola (Berk. e M.A. Curtis) C.T. Wei, é o agente etiológico da macha-alvo, doença relatada em mais de 530 espécies de plantas, incluindo mono e dicotiledôneas (3).

Na região Norte do Brasil, a mancha alvo apresenta importância econômica, tanto em cultivos em campo aberto como protegidos, sendo considerada como uma das principais doenças das partes aéreas de cucurbitáceas e solanáceas (4).

Epidemias de mancha-alvo em pepineiro (Cucumis sativus L.) foram relatadas em cultivos protegidos no Norte do Estado do Paraná, causando perdas de até $60 \%$ da produção de pepino "tipo japonês" (7). No Estado do Amazonas, esta doença causa prejuízos aos produtores de pepino, tanto em cultivo protegido como em campo aberto.
O plantio de cultivares resistentes constitui o método mais eficiente, racional e econômico para minimizar os danos causados por fitopatógenos. É necessário avaliar continuamente o comportamento de genótipos em relação às doenças, para direcionar estudos futuros de melhoramento visando à obtenção de cultivares resistentes, e para orientar a escolha e a recomendação de cultivares por parte dos produtores. O presente trabalho teve como objetivo avaliar a reação de dez genótipos de pepineiro a C. cassiicola em casa de vegetação.

$\mathrm{O}$ experimento foi conduzido em delineamento inteiramente ao acaso, com dez repetições, sendo cada unidade experimental constituída por uma planta. Como testemunha foram consideradas plantas dos genótipos avaliados, tratadas com água destilada 
esterilizada. Foram avaliados os genótipos 'Aodai', 'General Lee F1', 'Hokushim', 'Japonês Híbrido F1' (Soudai), 'Joia', 'Marketmore 76' (verde comprido), 'Natsubayashi', 'Natsu Suzum', 'Sprint 440 II' e 'Tsuyataro'. Os genótipos foram cultivados em vasos de plástico de $180 \mathrm{~mL}$ de capacidade contendo o substrato Plantimax HT $^{\circledR}$.

Os isolados de $C$. cassiicola foram obtidos de plantas de pepineiro apresentando sintomas típicos da doença, coletadas em cultivos em Manaus-AM e Iranduba-AM, O isolamento foi feito pelo método indireto (1). Culturas monospóricas dos isolados foram obtidas e o inóculo multiplicado em placas de Petri contendo meio de cultura BDA, durante 10 dias a $26^{\circ} \mathrm{C}$ em câmara tipo B.O.D sem fotoperíodo. Para a inoculação foi selecionado um isolado procedente do município de Iranduba-AM, que apresentou produção abundante de esporos.

As plantas foram inoculadas aos 30 dias após a germinação, via pulverização de uma suspensão de inóculo na concentração de $10^{4}$ conídios $\mathrm{mL}^{-1}$ na superfície adaxial das folhas. Após inoculação, as plantas foram mantidas em câmara úmida por $48 \mathrm{~h}$ e em seguida foram mantidas em casa de vegetação em temperatura ambiente. Foi realizado o reisolamento do patógeno a partir das plantas inoculadas.

A severidade da doença foi avaliada em dias alternados, durante dez dias por meio da escala de notas (5) onde: $0=$ ausência de sintomas; $1=<1 \%$ de área foliar afetada (afs); $2=1$ a $3 \%$ de afs; $3=3$ a $6 \%$ de afs; $4=6$ a $12 \%$ de afs; $5=12$ a $25 \%$ de afs; $6=$ 25 a $50 \%$ de afs e $7=>50 \%$ de afs.

Os dados obtidos foram submetidos a ANOVA e as médias comparadas pelo teste de Tukey ao nível de 5\% de probabilidade utilizando-se o programa $\mathrm{SAEG}^{\circledR}$ versão 9.1. Com os dados de severidade foi calculada a área abaixo da curva do progresso da doença (2).

Os genótipos de pepineiro avaliados apresentaram diferentes níveis de severidade da mancha-alvo $(\mathrm{p} \geq 0,05)$ de acordo com os valores da área abaixo da curva do progresso da doença (Tabela 1).

A cultivar Aodai apresentou o menor valor de área abaixo da curva do progresso da doença (AACPD), considerada resistente, em comparação ao híbrido 'Tsuyataro' o mais suscetível.

Oliveira et al. (5), avaliando a reação de híbridos de pepineiro contra C. cassiicola em cultivo protegido no Norte do Paraná, relatam que o híbrido 'Tsuyataro' foi o mais suscetível aos isolados testados, e o híbrido 'Natsubayashi' o mais resistente. Teramoto et al. (6) estudando a reação de nove híbridos de pepino japonês a C.cassiicola em casa de vegetação, constataram que o híbrido 'Tsuyataro' foi o mais suscetível em comparação aos híbridos 'Taisho', 'Nikkey', 'Safira' e 'Yoshinari’ mais resistentes ao patógeno.

A durabilidade da resistência das cultivares em campo pode ser comprometida pela diversidade genética de fitopatógenos. Dixon et. al (3) avaliando a diversidade genética de 143 isolados de C. cassiicola de diferentes hospedeiras e regiões geográficas, evidenciaram a ocorrência
Tabela 1. Área abaixo da curva de progresso da doença (AACPD) em dez genótipos de pepineiro inoculados com Corynespora cassiicola.

\begin{tabular}{ll}
\hline Genótipos & AACPD \\
\hline Aodai & $386,88 \mathrm{~d}$ \\
Hokuchin & $1244,64 \mathrm{c}$ \\
Soudai & $1608,24 \mathrm{c}$ \\
Verde Comprido & $1735,68 \mathrm{c}$ \\
Natsubayashi & $1950,96 \mathrm{c}$ \\
General Lee F1 & $2981,52 \mathrm{~b}$ \\
Sprint & $4555,68 \mathrm{~b}$ \\
Jóia & $4724,88 \mathrm{~b}$ \\
Natsu-suzumi & $5401,92 \mathrm{~b}$ \\
Tsuyataro & $7390,80 \mathrm{a}$ \\
\hline
\end{tabular}

Médias seguidas pela mesma letra não diferem significativamente entre si pelo teste de Tukey $(\mathrm{p} \geq 0,05)$.

de alta diversidade genética dentro da espécie, possivelmente devido a mutações.

Para recomendações futuras de plantio de pepino no Amazonas deve ser avaliado o desempenho em campo dos híbridos 'Hokushin', 'Soudai', Verde Comprido e 'Natsubayashi' em comparação à cultivar 'Aodai'. É possível recomendar que sejam evitados o cultivo dos híbridos 'Tsuyataro', 'Sprint 440 II', Natsu Suzumi' e 'Jóia' em locais onde exista histórico da ocorrência de C. cassiicola, devido à suscetibilidade registrada.

\section{REFERÊNCIAS BIBLIOGRÁFICAS}

1. Alfenas, A. C.; Ferreira, F. A.; Mafia, R. G.; Gonçalves, R. C. Isolamento de fungos fitopatogênicos. In: Alfenas, A. C; Mafia, R. G. (Ed.). Métodos em fitopatologia. Viçosa, MG: Editora da UFV, 2007. Cap. 2. p. 53-90.

2. Campbell C. L.; Madden, L. V. Introduction to plant disease epidemiology. New York: John Wiley \& Sons, 1990. 532 p.

3. Dixon, L. J.; Schlub, K.; Pernezny, K.; Datnoff, L. E. Host specialization and phylogenetic diversity of Corynespora cassiicola. Phytopathology, v.

4. Lopes, C. A.; Reis, A.; Boiteux, L.S. Doenças fúngicas. In: Lopes, C .A.; Ávila, A. C. (Ed.). Doenças do tomateiro. Brasília, DF: Embrapa Hortaliças, 2005. p. 17-51

5. Oliveira, R. R.; Vida, J. B.; Tessmann, C. J.; Aguiar, B. M.; Caixeta, M. P. Reação de híbridos de pepino para cultivo protegidos a isolados de Corynespora cassiicola. Fitopatologia Brasileira, Brasília, DF, v.31, n.5, p. 509-512, 2006.

6. Teramoto, A.; Martins, M. C.; Ferreira L. C.; Cunha, M. G. Reaction of hybrids, inhibition in vitro and target spot control in cucumber. Horticultura Brasileira, Brasília, DF, v.29, n, 3, 342-348, 2011.

7. Versignassi, J. R.; Vida, J. B.; Tessmmand, J. Epidemia de mancha de corinespora em pepino "tipo japonês" sob cultivo protegido na Região Norte de Estado do Paraná. Fitopatologia Brasileira, Brasília, DF, v. 28, n. 5, p. 570, 2003. 